\title{
Measuring the Results of Creative Acts in R\&D: Literature Review and Perspectives
}

\author{
Luc Burki and Denis Cavallucci \\ INSA Graduate School of Science and Technology of Strasbourg \\ 24, Boulevard de la Victoire, \\ 67084 Strasbourg Cedex, France \\ \{luc.burki, denis.cavallucci\}@insa-strasbourg.fr
}

\begin{abstract}
In their work on the C-K theory, Le Masson et al talk about the passage from $R \& D$ to $R I D$, claiming that $R \& D$ in the era of innovation must revise its practices to adapt to the changes that have given birth to this new industrial paradigm. The authors speak of 'performance logic' as an incontrovertible step in this evolution without going any further into their thoughts on the matter. Only a few syntheses exist to allow us to understand the contributions that aim to qualify the inventive performance of $R \& D$, this article puts forward an analysis and provides a literature interpretation on this subject. We then discuss three main points in accordance to what seems to us to be appropriate for the future metrics of inventive efficiency.
\end{abstract}

Keywords: Innovation, Inventive metrics, Creativity, Computer Aided Innovation, TRIZ.

\section{Introduction}

Whether it be physical or intellectual, man has always aimed to measure his performance. Today, this is even more so the case in the industrial world and especially within companies. Whether this is provoked by external factors or driven by a more personal willingness, performance measuring takes hold as soon as an individual desires to progress and to commit themselves to this thought process. Our industry already entered into an era of innovation over a few decades ago. Like all changes of era, industrial practices feel the effect of evolution and must themselves evolve with it. The impact of the arrival of an era of innovation inevitably ends in the future emergence of a norm that requires companies to adhere to a legitimate model from a superior authority (rather than a model that would only work for a given company). Therefore, innovation must be structured and organised within a company to go beyond the management and marketing speeches.

While innovation is the subject of much relevant research regarding its measurement [1], less research has found that the role of finding creative within it. This is mostly due to vague relationships between creativity and innovation. We decided to concentrate on the latter in this paper with a twofold objective: clarifying the fuzzy relationships between ideas, inventions and innovation and analyzing litterature on the creative side of design projects and its measurements. 
Currently, not many measuring methods are available other than productive performance, qualitative or financial measurements. And yet, this measuring requirement is seen in a growing number of companies regardless of their activity. To achieve this goal, it implies the establishment of procedures that of course target innovation, but which also reference notorious methods and tools so that a future norm can accept and verify the robustness and the reproducibility (or just simply whether it works) of the inventive capacities of a particular company. However, at present, very few tools (except those derived from creative stimulation such as brainstorming, 6 thinking hats or synectics) support the creative stages of project groups within companies.

\subsection{The CEN389 Project}

This future European innovation norm is not just a simple hypothesis; preparatory work for 2015-2017 has already seen the light of day and it reinforces the idea that an innovation measurement, even one that is difficult to set-up, seems inevitable [2]. Indeed, if the European Community decides to go ahead with the creation of a norm, one can easily anticipate that the industry will rapidly become concerned with the impacts and stakes involved with this norm. At present, this norm is conceived to be an innovation stimulant and the European Commission identifies 9 key actions which lead to the standardisation of innovation and which contribute to innovation in a very significant way as well as to the competitiveness of European companies. These include:

- Reaffirmation of the commitment to a standardisation focused on the market and the voluntary use of norms.

- Recognition of the importance of innovation norms, both formal and informal.

- The concentration of efforts on the elaboration of norms for the global market.

- To facilitate the inclusion of new perceptions in the norms.

- To improve the access to standardisation for all stakeholders (mainly Small and Medium-sized Businesses (SMB), users/consumers and researchers).

- To remove the obstacles which obstruct an effective application and use of the norms (the lack of visibility, complexity, incertitude on the norm conformity or even rival norms).

- To take into account the existing correlations between Intellectual Property Rights (IPR) and standardisation.

- To pursue the on-going reform process by European Standards Organisations (ESO).

- To take into account the evolution of European economic and social needs as well as the changes in international context, both economically and politically.

The desire to take this norm on board will invariably generate significant methodological and structural changes for a company. These necessary procedures also place the company in the best possible position to access new markets in the era of innovation. It is therefore preferable to exist in a market aimed at helping to affirm capacities by obtaining this norm. This can be achieved via the implementation of methods, indicators or even procedures. However, rather than waiting for the 
consequences of the arrival of such a norm, anticipating it seems to be a more promising strategic choice. Finally, as with all stages of evolution, all changes within a company are reluctantly provided. Yet, to accompany a company into the era of innovation in the direction of its own inventive and innovative performance as well as its durability is the affair of everyone within the organisation.

\subsection{The DEFI Project}

We have fixed ourselves an objective: to contribute to these changes by involving some research in a project entitled under the acronym DEFI. This project has a goal: firstly, to understand and to characterise the notion of Inventive efficiency of Design activity and then to elaborate on the means of measurement of this efficiency in order to finally succeed in adopting an indicator that helps companies to locate their R\&D collective inventive capacities. Subsequently, companies which use this indicator can initiate the required actions to evolve in the desired direction, notably by accepting to evolve in their individual and group practices.

The measure of inventiveness in industry has very little, until now, been the focus of research. Only studies of performance measurements regarding routine design have been focused on. These studies provide usable indicators of after-the-event measurements whereas an activity that has been on-going must perform a "continuous" measurement. Nevertheless, one must agree to perform a synthesis on the existing contributions that conform to this ethos. This is the aim of the next section.

\section{Literature Synthesis}

An analysis of the existing literature on the subject of associated metric measurements of the inventive act in Design allows us to put forward several contributions. These contributions are formed from 3 different angled approaches of creative metric measurement: economic, productive and quantitative.

The economic approach: Using an economic approach we understand the financial measures and in particular the investment in R\&D. It represents the funds invested by the company in its $\mathrm{R} \& \mathrm{D}$ department or projects. This indicator is appreciated by economists and managers because it allows us for a functional R\&D expenses comparison between companies [3]. It also shows the importance accorded to innovation by the company and its desire to innovate [4]. Also note that the data concerning the R\&D of companies have always been used as an indicator of innovation [5].

R\&D expenses for example, are an investment; they create a durable input that in turn creates innovation. All this provides us with a measurement of capital that represents $R \& D$. The latter becomes an indicator, not only of the presence on an innovative activity, but also it is more appropriate than $R \& D$ expenses on their own [6]. Adding to this, this indicator remains simple to implement and easy to estimate and its regular use improves, amongst others, the comparison between the different studies from the same company. 
Concerning the time invested into research (including the time invested by the executives) this is an indicator used at the very first stages [7].

The productive approach: This measure is an evaluation of the results having a particular outcome. We found the following indicators: The number of patents requested and obtained, the patents citations indicated in the project and finally the time invested in research, i.e. the time spent by an engineer on a project. The number of patents conveying a quantitative measurement whereas the patent citations convey a qualitative measurement. The greater the number of patent citations, the greater the impact.

Lasting several years, patents as well as citations are an excellent method of inventive measure [8]. The patent is used as an indicator as it protects an idea, product of new mechanism, as a result we can ascertain the creative, inventive activity.

Patents are generally used as a database to create intellectual property indicators, but they can also provide indirect indicators of the efficiency of innovation investments [9]. Different approaches have been put forward shed light on the value of a patent. We find the patent citation to be an indicator of impact, the renewal fee which measures the value and data on the families of patents when the patent is introduced into another country (country where the patent is valid). A last value used in patents is the number of citations in the patent; this number is sometimes associated to its novelty level.

Another advantage is the availability of information (the fact that they are publicly released) and the formalisation imposed by the international authorities governing patents. This rigorous formalisation and availability are undeniable assets in semantic and syntactic research associated with patents.

Work which attests to the pertinence of patent citations as an invention or innovation quality indicator (in terms of the correlation between the internal subjectivity of the evaluation of the importance of patents by technical specialists and the number of patent citations) have already been the focus of several in depth studies [4].

Quantitative approach: This concerns the measurement of quantity and/or the quality of formulated ideas during a creative session. Here, we find indicators for the quantity of ideas per employee and the time spent on the creation/formulation of ideas.

The number of ideas per engineer per year is, for that matter, an indicator which can be used by a company during annual strategic planning. This approach sometimes has an objective to be reached for each engineer involved in the R\&D department of the company.

\subsection{Analysis of the 3 Approaches}

In this section we discuss the limitations of these indicators to put them into the perspective of our research issues. Investment in $R \& D$ is, without a doubt, a pertinent economic indicator, but this only provides us with a partial vision of the research efforts. In fact, this does not take into account the informal aspects associated with R\&D that often extend past the financial aspects to the engineer and scientific research aspects unique to the industry in question. This limitation is accentuated by the difficulty of recording in an accountable and financial way, the whole of the expenses assigned to $\mathrm{R} \& \mathrm{D}[10]$. In addition, such an indicator does not discriminate 
the research carried out by the company in secondary domains and subsidiary technologies, as they target the company's global investments and not the technological objects which are more concerned with R\&D [3]. Added to this is the limitation caused by SME's which do not possess an obvious R\&D department. Such an indicator remains highly contested in literature on this subject, including economic literature. Kemp et al for example [11] affirm that the R\&D studies under estimate the informal activities of small businesses.

In regards to patents records, we notice that not all new products, ideas or procedures are always patented [12]. Registering a patent depends on strategy and economic choice [8]. The problem linked to this type of indicator is that it is used in an essentially strategic goal and that not everything is patentable or patented [11]. Also, not all companies are necessarily capable of financially applying for patent [3].

Finally we conclude this analysis by the metrics surrounding the quantity of ideas. If we assume that at the beginning of the seventies there was a quantitative objective legitimised by the work of Osborn [13]. One point put forward by Osborn goes as far as to affirm that quantity gives birth to quality, thus the greater the number ideas the greater the chance of seeing creative ideas materialise. The other more recent analyses question these affirmations, notably that an idea does not express a degree of inventiveness and that the company is often powerless when faced with an over abundance of new ideas [14].

\subsection{Measuring Creativity: Myth or Imperious Necessity?}

Investigations into tests designed to measure the creativity of an individual have already been published as well as investigations into the management of creativity [15].

At the heart of these studies on this subject, creativity was perceived as a cognitive characteristic of artists or geniuses. For this reason its measure firstly targets the individual. The first models were therefore largely inspired from intelligence tests.

Three main categories can be seen:

1. Creative or divergent thinking tests [16].

2. Personality and biographic inventories: [17], [18], Creative altitude scale [19], Creative personality Test [20], "F" Test [21],

3. Measuring creativity according to 8 dimensions [22].

We then observe a need to distinguish the difference between those that reveal themselves as being creative producers and those that don't. So a notion of place and time appears and Kimberly et al push forward the idea that innovation can be new for the organisation implements it when it has already existed elsewhere. Companies are therefore interested in the measure of creativity, or rather its process, with performance being the goal. It is therefore simply a first concluding observation that the traditional methods of fixing objectives inhibit creativity. Researchers who lean towards this theme conclude that creativity cannot be managed and that the desire of companies to develop and drive managerial actions in favour of creativity inhibit it more than they favour it.

To support their affirmations, these authors put forward the idea that is it most necessary to understand what favours creativity in the heart of organisations but nevertheless creativity always resides in the personality of the individual. In addition, 
their interactions and the environment within which these individuals evolve determine their creative behaviour [23].

Another older notion put forward by Ford indicates that routine actions are the priority for creative actions [24]. A company that faces problems, regardless of their origin, will logically favour routine actions. They also put activities of a creative nature aside as in these conditions routine actions seem to guarantee security and survival.

We finish with the reluctances of creative measure; creative phenomenon does not correspond to that which a measurement imposes, because the measuring tools are in opposition with the essence of the creative process. This immeasurability is explained by the fact that by wanting to measure the fruits of the creative process we are looking to measure the unknown. A metrics measurement will only make sense when the process has been mastered. It shows that the creation of measuring instruments dedicated to the creative process cannot be profitable to the company because their use is not predetermined nor guaranteed.

Other more recent studies did not share these reluctances towards the measuring of the creative act. Among the most successful were Hernandez et al who put forward not only the notion of inventive efficiency measuring but also presented some interesting leads [25]. They observed and noted certain components unique to creativity that seemed to posses the pertinent attributes of the act of generating ideas including:

- The aptitude of stimuli provocation;

- The capacity to suspend judgement;

- The flexibility of representations;

- The aptitude to change reference system;

- The rapidity of incubation;

- The association to examples.

They then tested each of these particular traits in order to observe the individual's aptitude of possessing them. The measurement associated with this observation is divided in to 4 experimentally independent variables (quantity, quality, novelty and variety).

\section{Perimeter of Our Action}

We have seen different approaches that are sometimes conflicting in their perception of what is a creative act. However, before we look at 'what' and 'how' to measure, we asked ourselves the background of question of why we want to measure it.

At a glance the terms 'idea' 'innovation' and 'invention' are often perceived as synonyms whose edges of definition are sometimes blurred. It therefore seemed important to clarify the boundaries between these terms in another way other than by definitions upon which multiple pre-existing definitions would pile up and add confusion. So it is therefore by a schematic classification (namely the 3I) that we illustrate our subject. 


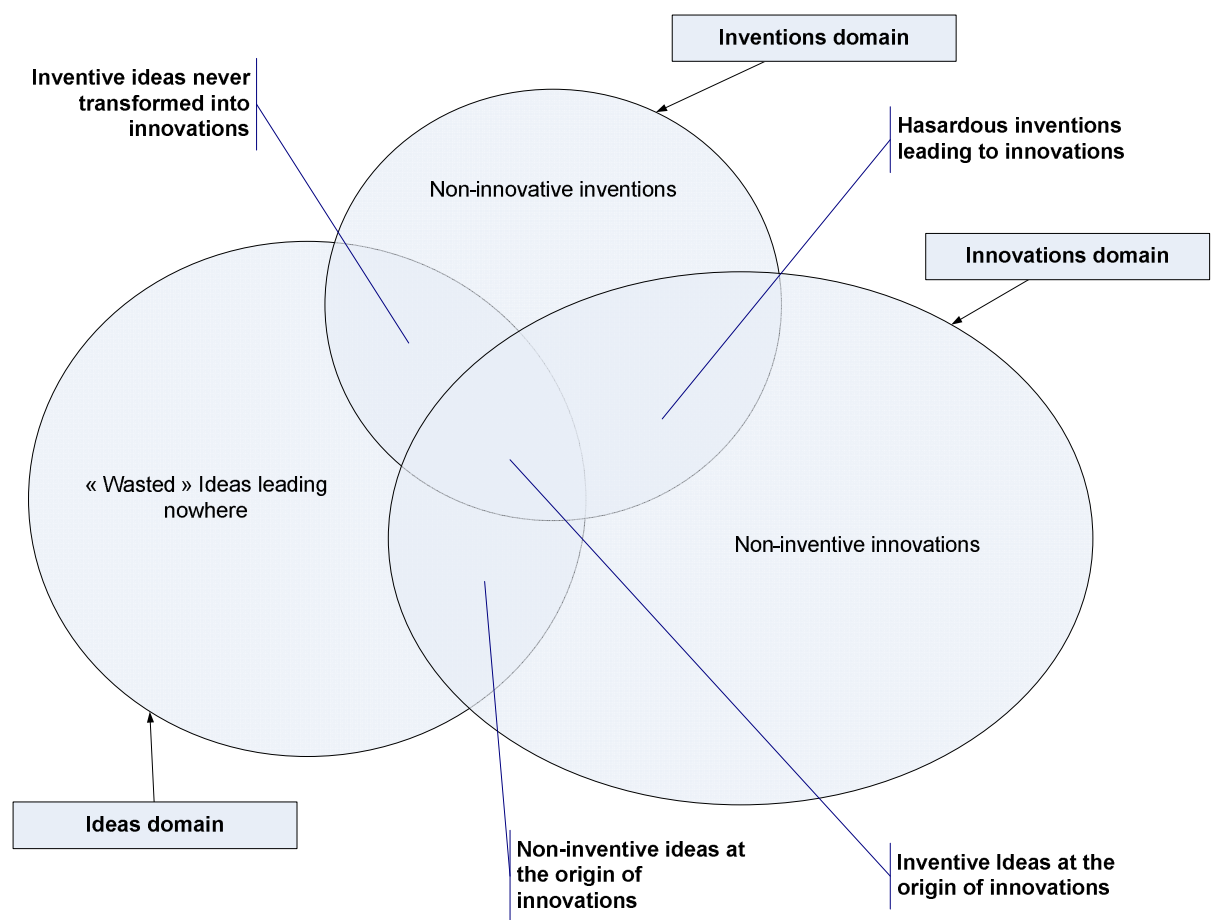

Fig. 1. 3I diagram for clarifying objects' fuzzy relationship with ideas, innovation and innovation

The chosen representation is composed of 3 spheres which represent the 3 basic "domains" (figure 1), i.e. ideas, inventions and innovations as well as their interactions:

- The idea sphere represents the intangible fruit of the imagination (structured or not) of the individual in the phase of concept generation.

- The invention sphere represents the plausible material aspect from the creative act, the new artefact that seems to be constructible but on a non-commercial basis remaining in the prototype phase.

- The innovation sphere that symbolises the encounter between an inventive proposition and a market that accepts it as new and plebiscite (sign of success).

Each sphere possesses a specific zone as well as shared zones and so offers interactions of particular significance:

- Inventive ideas represent not only the promozing ideas of innovators but also those which had not had market success.

- Innovating ideas are not only pioneering but also have market success.

- Innovating idea are ideas generated by improvisation (have not been subject to a particular problem solving attempt) and which have seen (by chance) success in the market. 
In our case, we accord a particularly high importance to the interconnection of these 3 circles, i.e. the inventive ideas of which the innovative vocation has been proved. The surface connection of these 3 spheres is certainly qualitative but it illustrates the meaning of our subject. The reality of the market shows a more significant section of non-inventive innovations. The 'wasted' ideas are obviously dominant, whereas the small percentage of inventive ideas that result in innovation is a minority. This could be explained by the fact that inventions often create a significant breakthrough and the market is not yet ready to welcome the invention (absence of need or need not yet affirmed). We could therefore imagine that the capacity of an idea becoming an innovation would be inversely proportional to the degree of inventiveness.

To give an example to better explain this image we try to discuss several products which are known to the general public and we target their possible localisation in this diagram previously mentioned.

- Iphone: This Smartphone is marketed as a collection of innovations but to locate the object as a whole we must divide it up into certain components. The 'multitouch' technology for example is already registered (therefore known) but not yet applied to mobile telephones. This could be an innovation because it stems from a non-inventive idea resulting in innovation. For its part the purchase of on-line applications is an innovative invention because it stems from a pioneering procedure, radically new, gaining notoriety in the domain and accepted by the target market. On the whole, we place the Iphone in the category of inventive innovations mainly due to its strategic software, marketing and communications more than for its hardware strategy and fabrication process which is essentially composed of solutions resulting in non-inventive innovations.

- The Dyson vacuum cleaner: For the first time, an inventive solution (using the 'vortex' technology (to separate air from dust and so to relinquish the bag during aspiration)) reaches its technological maturity to the point whereby it is released with success on the market. It is an innovative invention. We add also the particularity that the CEO of the group acts as the publicity icon during television advertising. This procedure is certainly an innovation, but non-inventive because others before him have already done this (Alain Afflelou or Luciano Benetton).

- The water Motor: Is an inventive idea as it relies on valid scientific foundations, but the technological maturity does not allow for the general public diffusion that could have granted it innovation status (no market success).

We now look at engineering projects of students in their last year of engineering curriculum. They endorsed a module namely "Inventive Design" (majorly supported by TRIZ tools). The starting point of such an approach is to invent the future of a currently existing object which targets the evolution trends of TRIZ and the solving of contradictions. The situation of engineers' project analysis is interesting and dissociates from an after-event-analysis such as those we have already mentioned in the last paragraphs. Indeed, it is easy to estimate the impact of a product known to the general public on a market after its launching. It is more difficult, but also more challenging to observe the fruits of an inventive project that has not yet attempted to be released on any market. The following objects have been analysed in order to identify their possible localisation in the 3I diagram: 
- The kettle: The proposed improvements are to make the system more water tight to increase the internal pressure and so favour a rapid increase in liquid temperature. One of the solutions envisaged by the group is to put the water in motion (like vibrating the heat resistance) to create a convection movement and so allow the water to heat more quickly. Finally, a separation of systems in order to only transport the packaging and not the whole system in concerns for weight and manageability aspects. When we look at these improvement propositions in themselves they are not inventive as they already exist for other systems, but their application in this case could be revealed as innovative if we base it on the novelty of domain application. We estimate therefore that the proposition of the kettle is a weak inventive proposition with the vocation of becoming an innovation (as the success of societal acceptance cannot be measured until afterwards).

- The Fins: This team proposed the use of a shear thickening material (that hardens on the mechanical shaking action that puts the fins into motion) in a tube that covers the fins of the flippers in order to optimise muscular effort. Such a concept is very inventive as it generates a significant technical break through on the basis of a real physical concept (thixotropy), however, whether it will gain societal acceptance that would lead this invention towards innovation status is still very uncertain. We are therefore more so in favour of an invention for which the innovation status is still unclear.

While evaluating the impact of a product (or an intention of product) in terms of its innovative potential has been at the heart of several researches [26][27], we have tried to highlight novel component of an evaluation that were in our mind missing for a more relevant metric of inventiveness. In that regard, two sub-metric measurements are to be considered:

1. That which qualifies the degree of inventivness. Like Altshuller who identified it by observing the distance between the origin of the solution with the origin of the invention and the domain within which the initial problem belonged to [28]. We can therefore talk of invention in different degrees (5 according to Altshuller) before giving hypotheses on the future of these inventions.

2. That which qualifies the reliability of the potential innovation. The aptitude according to which an invention has the chance to become an innovation, to minimise the risk associated with the incertitude of market success [29]. In this sub-metric measurement we can also bring forward the incertitude associated with the scientific and technical reliability of the idea. In other words, does the idea seem in itself scientifically plausible or is there a long way to go before we can rely on it without too much of a risk?

\section{Discussions}

In this section, we wish to highlight some existing tool materials and techniques in support of the creative act in Design. The goal is to explain the reason behind that which exists does not allow us to assume the metrics of the creative act imposed, as explained in the last section and that deeper investigation into this subject is necessary. Certainly, attempts can sometimes make the news, announcing new 
techniques proposing different and original approaches. It is therefore necessary to observe them in order to estimate if they resolve in part or its entirety the problems exposed. Last, TRIZ has been undeniably a key word repeated again since two decades in a recurrent fashion in the industrial, scientific and methodological world. We have devoted a significant part our discussion to it.

\subsection{Brainstorming Reaches Its Limit in the Era of Innovation}

The findings on the inefficiency of brainstorming in the current context of innovation exceed themselves. More broadely, creativity sessions in general are pointed out as unable to adress problems' complexity of the current industrial era. Besides this, creativity does not obey any rule, principle or even law; it can therefore difficultly be obtained "on demand". To attempt to dope creativity by asking too much of the human brain exposes us to the risks of an under performance as all that it (creativity) 'occupies' risks being inhibited. Stroebe and al in [30] proved that the rules of brainstorming (to favour the quantity of ideas, to encourage unusual ideas and to discourage criticism) is suitable for the production of ideas but that brainstorming delivers the best results when the groups have not had any pressure from management. Mullen et al in [31] presented a loss of productivity when brainstorming was practised by large groups. They therefore favour the use of this technique on an individual scale or in a group of two people. The problem faced is the expectation of the participants concerning voicing their opinions and so slowing down the enthusiasm surrounding the production of ideas.

However, the era of innovation demands go beyond the search for quantitative performance. The deliverable ideas from a creative session are provided more quickly for a reduced number of concepts and emerge as a very small number as they have already been trimmed down, for example, by the precise questioning of the wording of the objectives. The whole thing preserves the inventive aspect of ideas as the pool of reflection goes beyond that of the restrained circle of individuals capable of investigating.

\subsection{TRIZ Emerges as a Potential Lead but Does Not Impose Itself}

The novelty of the approach proposed in TRIZ very quickly seduced the large groups with the originality of its foundations and the rigour of its implementation. Whereas other tools seem mainly correlated to individual or group creativity, techniques derived from TRIZ seduces by their apparent capacity to broaden the field of possibility in the search for structured solutions. The fact that existing software tools come in support of its implementation is also a factor that favours its use in the industry.

Yet TRIZ will have its share of obstacles concerning its integration into companies. Indeed, to use it in a trimmed down manner [32] it is hardly even necessary to control the slightest of details in order to be able to provide the solution to multidisciplinary and complex problems. A significant training and often a change of mind is essential.

Whereas some people see TRIZ as an 'invention machine' [33] a realist observation makes them understand that its use calls into question significant 
structural and organisational handling within the practices of a company and that all changes in the industry are often accompanied by disagreeable difficulties.

However TRIZ was described by Alshuller as a theory, its potential methodological potentials are almost infinite. One can therefore legitimately think that the original and theoretical aspects developed by Altshuller (notably the concept of contradiction and the notion of evolution law) could be noted as fundamental to the reconstruction of new industrial practices adapted to the problems of the era of innovation. However, bearing in mind what the professionals from the world of TRIZ have up until now produced, nothing emerges in a legitimate way as if it was the model for the whole industry to follow.

However, several study findings have demonstrated the aptitude of TRIZ to be more prolific that other methodological approaches concerning its pro rata of inventive ideas in comparison to the quantity of 'waste' ideas [34]. Where the other approaches concentrate on the quantity (Osborn model), TRIZ focuses on the guarantee of the inventive aspect of a concept before accepting its presence on a list. However, every concept must make sense of the given contradiction engaged in resolution, which other approaches don't do; they fully unleash the act of ideation, accumulating more waste ideas more than those which effectively resolve a problem. Finally, adding the necessarily unpredictable side of the classic creative approaches, contrary to TRIZ that organises itself in a pragmatic way and issues all its potential in the time limits which are correlated to the complexity of the problem to be resolved, but all the same, are estimable beforehand. Today, companies find themselves restrained to reducing the cycles linked to projects in order to increase the number and their competitiveness. One easily understands that an approach based on the unpredictable rapidly reaches its limits in such a situation.

In a comparative table, Fantoni et al put forward an important point: only TRIZ systematises the use of a vast basis of multidisciplinary knowledge [34]. This allows us to use tools or methods designed to:

- Reduce the incertitude by relying on existing data;

- To systematically organise thinking out of the box of what is known within the company (or the study group) and so favouring the growth of the value of inventive ideas.

To help companies correctly choose the most adapted tool, Fantoni et al have performed a class system of problem resolution methods. They have selected the methods the most widely available in not only the industrial world but also in the academic world. Their first analysis covers the force of the existing links between a given method and the different generic steps of a Design project. Each method is attributed a value between strong and weak to qualify these links. As a matter of fact no method is ideal but TRIZ (envisaged here under the angle of a method) finishes ahead in this comparison.

A second comparison puts forward the essential expected characteristics of a method and a measurement in accordance to 3 values is performed (yes, no and a mean value). Once again TRIZ comes out first as the only method having obtained a positive value for each characteristic. This study shows that TRIZ seems appropriate to inspire the construction of new methods aiming at satisfying the engineers faced with their Design difficulties in the era of innovation. Nevertheless, the paradox 
persists; while way ahead in comparison to other approaches, TRIZ in its current shape does not convince industrialists sufficiently to adopt it. Hence a questioning appears as a perspective of future works: which role could TRIZ have in the construction of a new method to make company R\&D practices evolve?

\subsection{Three Leads for an Inventive Design Efficiency Metrics}

On the basis of the literature analysis and the trends on the subject of creativity metrics we observe the finding that brings the communities together: everyone agrees that it is legitimate for a company to aspire to measure it creative capacities. Certain work then shows why this is not possible, other attempt to contribute to this problem by being a strength of proposition. In the DEFI project described in the introduction of this article, we fall under this second circle of influence of contributors, in keeping in mind the legitimate reluctance of researchers that are opposed to the measuring of creativity. The three main outlines of our work are based around 3 points that are firstly aimed at redesigning the perimeter that is seen by avoiding the trap of measuring the fruits of the human mind. We consider that the company group acting as a team for whose results exceed the simple sum of individual performances.

In the next section, we define our orientation of research for a company inventive capacity metrics.

\section{Point 1: Favour the production of "inventive ideas" versus "ideas of any kind"}

If the envisaged production of ideas under the angle of quantity is not the priority, the objective of rapid emergence of these ideas seems more legitimate. An adapted metrics system must therefore observe the fluctuations in creative production results by estimating the time lapse that separates the instant where the problem exists from when the solution arose. In the same way, the regularity of a performance is proved at the end of an investigation (or miscellaneous solicitations); it attests that the group of agents involved control the creative process with more or less ease. So as not to bias such a measurement, the inventive value of solutions cannot attest to a success alone. This is because it would be easy to remember only the released ideas and those imagined in use in the invention. The ideas which must be considered as a solution is not every possible idea, but only those that focus on the developmental decisions, i.e. those that the company would focus $R \& D$ expenses on.

\section{Point 2: Favour the "collective pugnacity" for transforming inventions into innovations}

The settings of our thoughts is focused on the breakthrough projects, these project are exclusively covered in the measurements. The routine projects, for their part, will not intervene in the invention metrics. However, when a company's product requires open reflection on invention, the capacity of all the agents responsible for creative productions must let their aptitude come forth so as to accept what is routinely released by the company, not in a risky way but in an opportunistic way. The refusal of risk and systematic reflex is to distance yourself from it, to go back to the reassuring aspect is in no case inventive and should be estimated in the inventive metrics. It is the regularity with which a company (via the intermediary of its agents) accepts to face the unknown within its $R \& D$ department which could be a significant component of inventive performance. 


\section{Point 3: Do not under-estimate the difficulties linked with adoption}

In addition to the creative production performance aspects, a measurement only makes sense if it qualifies an aptitude associated to the outcomes of the company. Yet, the company must reach its target market with success in order to prosper. Only the inventivness of concepts would not be estimated, one must add it to the impact of the group that represents the whole chain of company agents, from the manager to the operational staff and their confirmed desire to act as a team for the success of the inventions. However such a measure, as it is not certain until after the event, cannot rely on the shifted observations over time. It is in that instant that an invention metric must serve to indicate the capacities of the company, and not on the basis of past success stories. Such an indicator (stakeholder of a more global indicator upon which we are working) should observe the decisional chains of the company as a flow through which we must estimate their capacity to encourage inventions.

\section{Conclusions}

The scientific literature on the subject of measuring the creative act's results is abundant. Two contributing scientific domains stood out. Human and social sciences, more precisely cognitive sciences, which show the products of the mind and analyse its mechanisms and the climate within which it is most opportunistic to place the product. Managerial and economic sciences, which focus on the organisation, nature, typology and contextual reason (financial and market) prove to be efficient in the matter of innovation. In this article, we expose a point of view that reveals engineering science by focusing on the R\&D actor, the project and the company within which its activity is registered and the scientific and technical value of its cognitive productions conveyed by resolved problems pertaining to the object conceived.

This article is a preamble to a future metric of inventive efficiency by carrying out a synthesis and by analysing the literature on this subject. We then adopt a particular point of view and expose it with a discussion section through which we also present how we will organise the future research on this subject. Three points, where a measure is necessary have been defined and discussed. They constitute three major outlines of this research. To indicate that which must be observed, the context explains the positioning of an available artefact on the market or the fruits of an $R \& D$ design project according to the 3I diagram. This allows us to come to terms with the complexity of qualifying a new idea and indicating its status (from a wasted idea to an inventive idea leading to an innovation).

To finish, our article explains that the arrival of techniques derived from TRIZ on the scene of creative tools gains popularity from companies but only brings partial enlightenment to level out the cognitive, social, managerial and procedural difficulties of the company when faced with its desire to innovate. This last component is therefore promising in terms of it foundations and will be useful to take into account during the stages of inventive progress of a company. However, an efficient legitimate indicator in the industry will see the light of day and there is still a substantial distance to go before we achieve this. 
Yet, the arrivial of the CEN389 project from the European Community replaces the challenge of invention measuring which was at the forefront of the industrial medium term manager's and industrial researches preoccupations. The immediate consequence of this project is that the measurement of the creative act which was described only as a utopia a decade ago has now become a legitimate object for which pragmatic results prove to be more than necessary.

\section{Acknowledgments}

First of all we would like to thank the competitivity centre 'Véhicule du futur' for having backed our project; Also to the Région Alsace and the FEDER for financially supporting this project. Secondly we wish to thanks the partner companies, notably MARKIV, FAURECIA and COOLTECH for their time dedicated to our interviews and debates that we had on the subjects related to in this article. Finally thanks to AFNOR for the organisation of regular work session on the management of innovation for the project CEN389.

\section{References}

1. Rejeb, H.B., Morel-Guimarães, L., Boly, V., Assiélou, N.G.: Measuring innovation best practices: Improvement of an innovation index integrating threshold and synergy effects. Technovation 28, 838-854 (2008)

2. Barthet, M.: La normalisation creuse le champ de l'innovation (2009)

3. Godin, B.: L'état des indicateurs scientifiques et technologiques dans les pays de l'OCDE. Projet de remaniement des sciences et de la technologie, Statistique Canada

4. Hagedoorn, J., Cloodt, M.: Measuring innovative performance: is there an advantage in using multiple indicators? Research Policy 32, 1365-1379 (2003)

5. Marklund, G.: Indicators of innovation activities in services. Services and the KnowledgeBased Economy 86 (2000)

6. Rao, P.S., Sharpe, A.: Les enjeux de la productivité au Canada. University of Calgary Press (2002)

7. Miller, W.L., Morris, L.: Fourth Generation R\&D: Managing Knowledge, Technology, and Innovation. Wiley, Chichester (1999)

8. Kabla, I.: Un indicateur de l'innovation: le brevet. Économie et Statistique 275, 95-109 (1994)

9. Dodgson, M., Hinze, S.: Indicators used to measure the innovation process: defects and possible remedies. Research Evaluation 9, 101-114 (2000)

10. Munier, F., Rondé, P.: The role of knowledge codification in the emergence of consensus under uncertainty: empirical analysis and policy implications. Research Policy 30, 1537-1551 (2001)

11. Kemp, R.G.M., Folkeringa, M., De Jong, J.P.J., Wubben, E.F.M.: Innovation and firm performance. EIM (2003)

12. Crépon, B., Duguet, E., Mairesse, J.: Mesurer le rendement de l'innovation. Economie et statistique 334, 65-78 (2000)

13. Osborn, A.F.: Applied Imagination. Scribner (1953)

14. Glassman, B.: Improving idea generation and idea management in order to better manage the fuzzy front end of innovation (2009) 
15. Auger, P.: Mesurer ou créer? Contribution de la GRH à la performance Organisationnelle. UQAM, Montréal (2004)

16. Guilford, J.: Creativity. American Psychologist 5, 444-454 (1950)

17. Zuckerman, M.: Personality in the third dimension: A psychobiological approach. Personality and Individual Differences 10, 391-418 (1989)

18. Davis, M.A.: Understanding the relationship between mood and creativity: A metaanalysis. Organizational Behavior and Human Decision Processes 108, 25-38 (2009)

19. Schaefer, C.E.: Imaginary companions and creative adolescents. Developmental Psychology 1, 747-749 (1969)

20. Barron, F.: The disposition toward originality. Journal of Abnormal and Social Psychology 51, 478-485 (1955)

21. Eysenck, H.J.: Can we study intelligence using the experimental method? Intelligence 20, 217-228 (1995)

22. Torrance, E.P., Glover, J.A., Ronning, R.R., Reynolds, C.R.: Handbook of creativity. Springer, Heidelberg (1989)

23. Mumford, M.D., Gustafson, S.B.: Creativity Syndrome: Integration, Application, and Innovation. Psychological Bulletin 103, $27-43$ (1988)

24. Ford, H.: Today and Tomorrow. Productivity Press (1926)

25. Hernandez, N.V., Shah, J.J., Smith, S.M.: Understanding design ideation mechanisms through multilevel aligned empirical studies. Design Studies 31, 382-410 (2010)

26. Patterson, F.: The Innovation Potential Indicator: Test manual and user's guide (2001)

27. Frenz, M., Ietto-Gillies, G.: The impact on innovation performance of different sources of knowledge: Evidence from the UK Community Innovation Survey. Research Policy 38, 1125-1135 (2009)

28. Altshuller, G.: Creativity as an exact science: the theory of the solution of inventive problems. Gordon and Breach Science Publishers, New York (1984)

29. Frenz, M., Ietto-Gillies, G.: The impact on innovation performance of different sources of knowledge: Evidence from the UK Community Innovation Survey. Research Policy 38, 1125-1135 (2009)

30. Stroebe, W., Nijstad, B.A., Rietzschel, E.F.: Beyond Productivity Loss in Brainstorming Groups: The Evolution of a Question. Présenté au (2010)

31. Mullen, B., Driskell, J.E., Salas, E.: Meta-Analysis and the Study of Group Dynamics. Group Dynamics 2, 213-229 (1998)

32. Turner, S.: ASIT-a problem solving strategy for education and eco-friendly sustainable design. International Journal of Technology and Design Education 19, 221-235 (2008)

33. Hollingum, J.: Invention machine - A machine for making inventions? Assembly Automation 18, 112-119 (1998)

34. Fantoni, G., Biasci, F., Bifulco, A., Santoro, R.: Collaborative Problem Solving in design methods: foundation elements for an integrated approach. In: Proceedings of ICE Conference, Milan, Italy, pp. 26-28 (2006) 